\title{
Assessment of Desertification in the Agro-Pastoral Transitional Zone in Northern China (1982-2006) Using GIMMS NDVI Data
}

\author{
Youzhi An ${ }^{\mathrm{a}, \mathrm{b}}$, Wei Gao ${ }^{\mathrm{a}, \mathrm{b}, \mathrm{c}}$, Zhiqiang Gao*d, Chaoshun Liu ${ }^{\mathrm{a}, \mathrm{b}}$, and Runhe Shi ${ }^{\mathrm{a}, \mathrm{b}}$ \\ ${ }^{a}$ Key Laboratory of Geographical Information Science, Ministry of Education, East China Normal \\ University, Shanghai, 200062, China; \\ ${ }^{\mathrm{b}}$ Joint Laboratory for Environmental Remote Sensing and Data Assimilation, ECNU and CEODE, \\ Shanghai, 200062, China; \\ ${ }^{\mathrm{c}}$ Department of Ecosystem Science and Sustainability, Colorado State University, Fort Collins, CO, \\ 80523, USA; \\ ${ }^{d}$ Yantai Institute of Coastal Zone Research, Chinese Academy of Sciences, Yantai, 264003, China
}

\begin{abstract}
The Agro-Pastoral Transitional Zone in Northern China (hereafter APTZNC) is situated in an arid/semi-arid area, and is one of the most vulnerable areas in the world subject to climate change. Annual integrated the NASA Global Inventory Modeling and Mapping Studies (hereafter GIMMS) Normalized Difference Vegetation Index (hereafter $\Sigma$ NDVI) and annual rainfall were used in this study. Meanwhile, the dynamics of $\Sigma$ NDVI and rain-use efficiency (hereafter RUE) were predicted during the period, through the use of the Mann-Kendall nonparametric test and linear regression temporal trend analysis. The tendency of desertification under different precipitation scenarios was also analyzed. The results showed that annual $\Sigma$ NDVI and rainfall were not significantly correlated in most sections of the study area, yet opposite results were observed for a smaller percentage of the study area $(\mathrm{p}<0.01)$. Changes in vegetation productivity may increase, whereas a significant decrease in a small pixel proportion was observed. The northeast and central sections of the study area are characterized by positive trends in RUE slope values, contrary to what was observed in the southwestern sections of the study area. The results fit well with the findings through $\Sigma$ NDVI and RUE. Rainfall in the range of $200-500 \mathrm{~mm}$ can be seen as a threshold value as the desertification trend decreases and vegetation restoration capacity is enhanced with increasing rainfall.
\end{abstract}

Keywords: Desertification, Agro-Pastoral Transitional Zone, GIMMS NDVI, RUE

\section{INTRODUCTION}

The United Nations Convention to Combat Desertification (UNCCD) is the sole legally binding international agreement linking environment and development to sustainable land management. UNCCD stated that "Desertification is caused by complex interactions among physical, biological, political, social, cultural, and economic factors" and "Land degradation is the loss of environmental services or the reduction of the biological and/or economic productivity" (www.unccd.int) .

Vegetation productivity and rainfall are two driving factors related to land desertification and degradation. Predicted

"gaoland@gmail.com; phone 86535 2109184; fax 8610535 2109184;www.yic.ac.cn

Remote Sensing and Modeling of Ecosystems for Sustainability X, edited by Wei Gao,

Thomas J. Jackson, Jinnian Wang, Ni-Bin Chang, Proc. of SPIE Vol. 8869, 886913

(C) 2013 SPIE · CCC code: 0277-786X/13/\$18 · doi: 10.1117/12.2021857

Proc. of SPIE Vol. $8869886913-1$ 
effects of climate change could not only change the precipitation pattern, but could potentially increase or decrease the rainfall, which would directly affect vegetation productivity. On the other hand, other abiotic factors (i.e., soil nutrients, temperature, growing days, and $\mathrm{CO} 2$ ) strongly affect vegetation productivity ${ }^{[1]}$. However, the debate regarding the potential impacts of climate change and human activities to land desertification and degradation still exist ${ }^{[2-4]}$.

Rain-use efficiency (RUE) was demonstrated as the ratio of aboveground net primary productivity (ANPP) to rainfall ${ }^{[5]}$. Spatial-temporal changes in RUE have been widely used in the assessment of land desertification and degradation ${ }^{[6,9-12]}$. Alternatively, the annually integrated normalized difference vegetation index ( $\Sigma$ NDVI) was used for the net primary production (NPP) ${ }^{[6-9]}$. Hellden et al. and Fensholt et al. analyzed the temporal dynamics in NPP using the AVHRR GIMMS NDVI dataset ${ }^{[4,9]}$. Temporal analysis of NDVI has been widely conducted, where NDVI time series data sets (i.e., the Spinning Enhanced Visible and Infrared Imager (SEVIRI) sensor onboard the geostationary satellite Meteosat Second Generation (MSG), Moderate Resolution Imaging Spectroradiometer sensor onboard the Terra platform (MODIS/Terra), and VEGETATION sensor onboard the SPOT satellites (SPOT/VGT)) were applied ${ }^{[12-16]}$.

The goals of this work are to: (1) analyze the spatial-temporal relationships between annual integrated NDVI ( 2 NDVI) and annual rainfall; (2) detect the inter-annual vegetation changes from 1982-2006; and (3) assess the effect of rainfall influence on the changes in land cover.

\section{DATA AND METHODS}

\subsection{Study area}

In this study, the APTZC refers to the ecological transition zone between agricultural areas and natural grassland. It is located between $101.1^{\circ} \mathrm{E} \sim 125.6^{\circ} \mathrm{E}$ and $34.5^{\circ} \mathrm{N} \sim 48.4^{\circ} \mathrm{N}$, including the major sections of Inner Mongolia, and smaller sections of Heilongiang Province, Jilin Province, Liaoning Province, Hebei Province, Shanxi Province, Shaanxi Province, Gansu Province, Ningxia Province, and Qinghai Province. The APTZNC is at the edge of the continental monsoon climate where the transition zone from the semi-humid area to the semi-arid area has an average annual rainfall of 189 654 $\mathrm{mm}$. The modes in agriculture production and animal husbandry are different. The main ecological problems in these regions are land desertification combined with grassland degradation and the loss of vast amounts of land nutrient resources ${ }^{[17]}$.

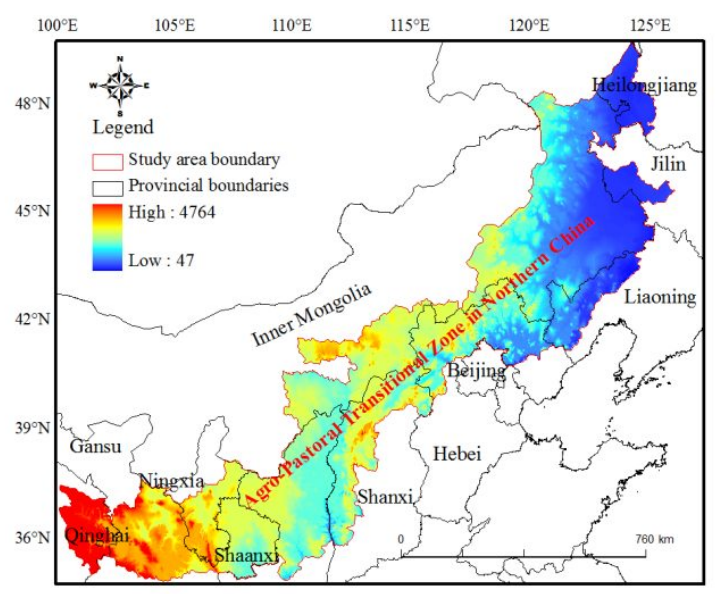

Fig.1. Location of study area, the APTZNC. 


\subsection{NDVI products}

The AVHRRGIMMS NDVI dataset was used in this study ${ }^{[4,9,18,19]}$. The data source in this time series from 1982 to 2006 was collected from the Global Land Cover Facility (GLCF) data center ${ }^{[18]}$. The GIMMS NDVI was produced at a spatial resolution of $8 \mathrm{~km} \times 8 \mathrm{~km}$, and the temporal step was 15 days. A common maximum value composite (MVC) approach is performed to compile monthly NDVI datasets observed by the AVHRR instrument onboard the NOAA satellites (series 7, 9, 11, 14, 16, and 17), as to reduce the effects from clouds, noise, and artifacts due to satellite drifft ${ }^{[16]}$. This NDVI dataset has been corrected for calibration, sensor degradation, orbital drift, view geometry, cloud cover, volcanic aerosols, and other effects that are not related to changes in vegetation ${ }^{[18]}$.

In order to avoid the influence of negative values of water body, clouds, and other climatic factors, NDVI pixel values below zero were reassigned to zero and a Savitzky-Golay filtering method was applied to each annual $\mathrm{NDVI}$ dataset ${ }^{[20-22]}$. A predefined compositing period for each pixel of the highest values observed is selected for the MVC product, and represents the current period. The monthly and annual GIMMS NDVI dataset from 1982 to 2006 was interpreted using the MVC method. With the use of the monthly MVC GIMMS NDVI dataset, mean annual MVC NDVI during 1982-2006 in the study area was calculated and mapped (Fig. 2).

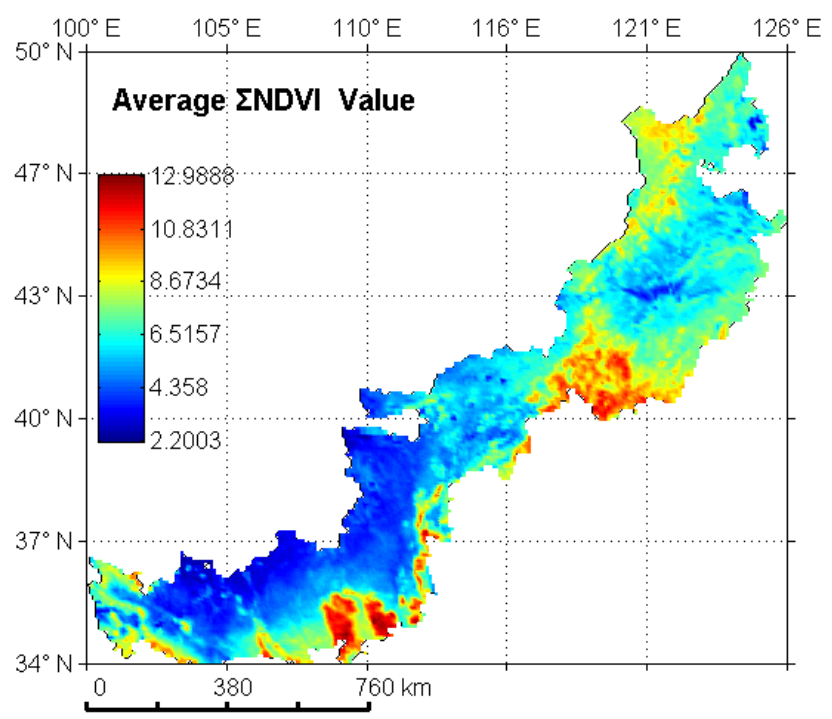

Fig.2. Average annual इNDVI in the APTZNC during 1982-2006.

\subsection{Rainfall data}

The annual rainfall data were collected from the National Meteorological Center of China. The data include observations at 95 meteorological stations during 1982-2006 in the APTZNC or its neighboring areas. For further analysis, the inverse distance weighted (IDW) interpolation method was used with ArcGIS software to produce the raster data with the same projection and spatial resolution of the NDVI datasets ${ }^{[23]}$. The spatial pattern of the average annual rainfall in the study region is shown in Fig. 3. 


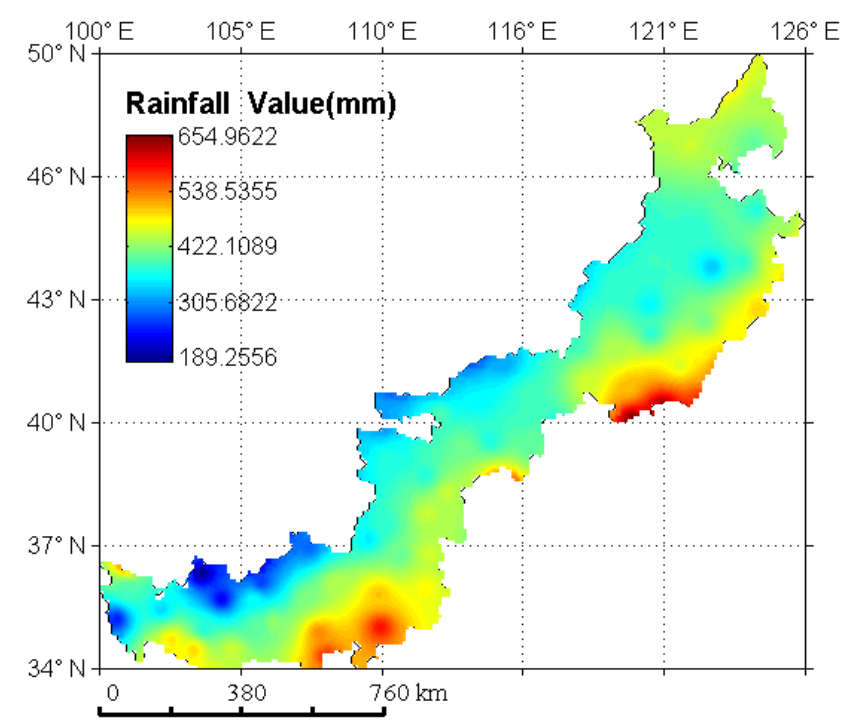

Fig.3.Average annual rainfall in the APTZNC during 1982-2006.

\subsection{Methods}

To understand the effects of rainfall on annual $\Sigma$ NDVI, the relationship between annual $\Sigma$ NDVI and rainfall were analyzed by the Pearson correlation method.

The significance of the annual $\Sigma$ NDVI in time series trends was calculated by the non-parametric Mann-Kendall significance test (M-K). The M-K non-parametric test is a good indicator of time series trends, thus it is widely used as a trend analysis method ${ }^{[1,24,25]}$. One advantage is that samples are not required for compliance with certain distributions, and the interference of a few singular values is avoided. The M-K statistic $U$ range is $(-\infty,+\infty)$ where $U>0$ time series is an increased trend and $U<0$ time series is a decreased trend. A positive slope $(U \geq 1.96)$ represents a significant increase $(\mathrm{a}=0.05)$ in NDVI for the period 1982-2006, and negative slopes $(\mathrm{U} \leq-1.96)$ indicate a significant decrease (a $=0.05$ ). In order to further investigate the annual $\Sigma$ NDVI and RUE trend, temporal trend of the datasets was examined by a simple linear regression model on a per-pixel basis. The analyses covered the years from 1982-2006 as the temporal coverage in $\Sigma$ NDVI and RUE datasets. The output of the trend analysis is the map of the slope that indicates the strength and extent of the annual $\Sigma$ NDVI and RUE trend. This approach represents a simple and powerful method to characterize long-term trends in the annual $\Sigma$ NDVI and RUE dataset. Because of the weak relationship between $\Sigma$ NDVI and annual rainfall, our results are only valid when both trends in $\Sigma$ NDVI and the $\Sigma$ NDVI-rainfall correlation are significant ${ }^{[9]}$.

\section{RESULTS}

\subsection{The relationship between annual $\Sigma$ NDVI-annual rainfall}

Pearson correlation analysis of GIMMS NDVI against rainfall for the period 1982-2006 is based on annual ENDVI and rainfall covering the study area on a pixel-by-pixel basis. The correlation coefficient is shown in Figure 4.

Areas in red represent strong and positive correlations $(0.5051<\mathrm{r} \leq 0.7605, \mathrm{p}<0.01)$, as shown in Figure 4 . This reveals that rainfall is the leading factor resulting in the vegetation dynamics in these areas, which can be defined as a 'normal' land condition ${ }^{[12,26]}$, generally found in the central and southern areas of the APTZNC. The positive correlation between 
$\Sigma$ NDVI and rainfall implies that rainfall effects $\Sigma$ NDVI. This situation accounts for $22.13 \%$ of the total area. However, only $5.49 \%$ of the total area is characterized by a significant positive relationship $(0.5051<\mathrm{r} \leq 0.7605$, $\mathrm{p}<0.01)$ (Fig.4).

Areas in blue show a significant negative correlation $(p<0.01)$, where the rainfall may increase while the $\Sigma$ NDVI decreases. These areas are characterized as the "worst" land conditions in the study area. In addition, $\Sigma$ NDVI and rainfall were negatively correlated, which accounts for $22.13 \%$ of the total area. However, only $0.32 \%$ is characterized by a significantly negative relationship $(-0.5952 \leq \mathrm{r}<-0.5072, \mathrm{p}<0.01)$ (Fig.4).

There was no significant correlation between the annual $\Sigma$ NDVI and rainfall at the $10 \%$ level (green areas in Fig.4). However, annual $\Sigma$ NDVI and rainfall are not significant for the remaining $74.80 \%$ of the total area. Thus the distribution of rainfall could not fully explain the patterns of vegetation growth.

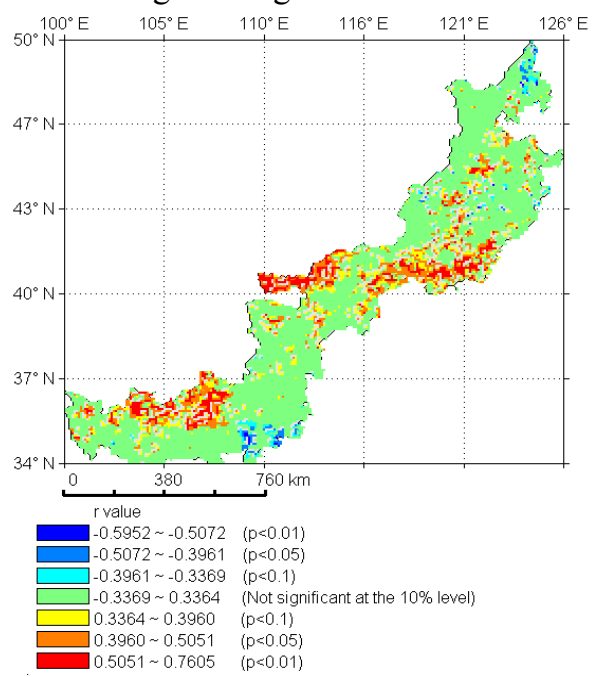

Fig.4. Map of r-values for the annual ENDVI GIMMS correlated with the annual rainfall in the APTZNC during $1982-2006$.

Only significant $r$-values at a $10 \%$ confidence level are included.

\subsection{Trends in annual $\Sigma$ NDVI}

The M-K test map and linear regression temporal trend analysis slope are derived from a pixel-by-pixel basis for the APTZNC area (Fig. 5). Varying degrees of change were demonstrated during 1982-2006 as shown in Figure 5. The changes in vegetation show an increasing trend, contrary to what was observed in the small pixel proportion. Areas (58.30\% of the pixels) in red represent significantly increased trends ( $\mathrm{U} \geq 1.96, \mathrm{a}=0.05)$ in $\Sigma$ NDVI during 1982-2006. Only $9.89 \%$ of the pixels show a significant decreased trend during the same period $(U \leq-1.96, a=0.05)$.

A greater share of positive trends vs. negative trends was observed for land cover change, simultaneously. Whereas positive trends were distributed in the northeast and central sections of the APTZNC, the reverse was detected in smaller areas $(\mathrm{p} \leq 0.05)$ of the southwest and northeast sections (Fig. 5). Even so, positive trends were also observed in the southwest and northeast sections of APTZNC (Fig. 5). The vegetation greening trend may be due to reforestation from farmland.

Figure 5 shows $\Sigma$ NDVI trends in the whole area during 1982-2006. A significant increase in trends can be observed in the main section of the study area. Even though the M-K test better explains the increasing trends $(68.19 \%, a=0.05)$ compared to the linear regression trend test $(39.13 \%, \mathrm{p} \leq 0.05)$, the conclusion between these two methods is consistent. 
The red areas in Figure 4 represent a 'normal' condition signifying the 25 -year change (a decreased trend), whereas the southwest (Huan, Dingbian and Yanchi Counties) and northeast (Balinzuo and Ongniud Banner) sections of the study area are primarily characterized by negative trends (Fig. 5). In other words, the rainfall does not seem to be a determining factor for controlling vegetation dynamics.
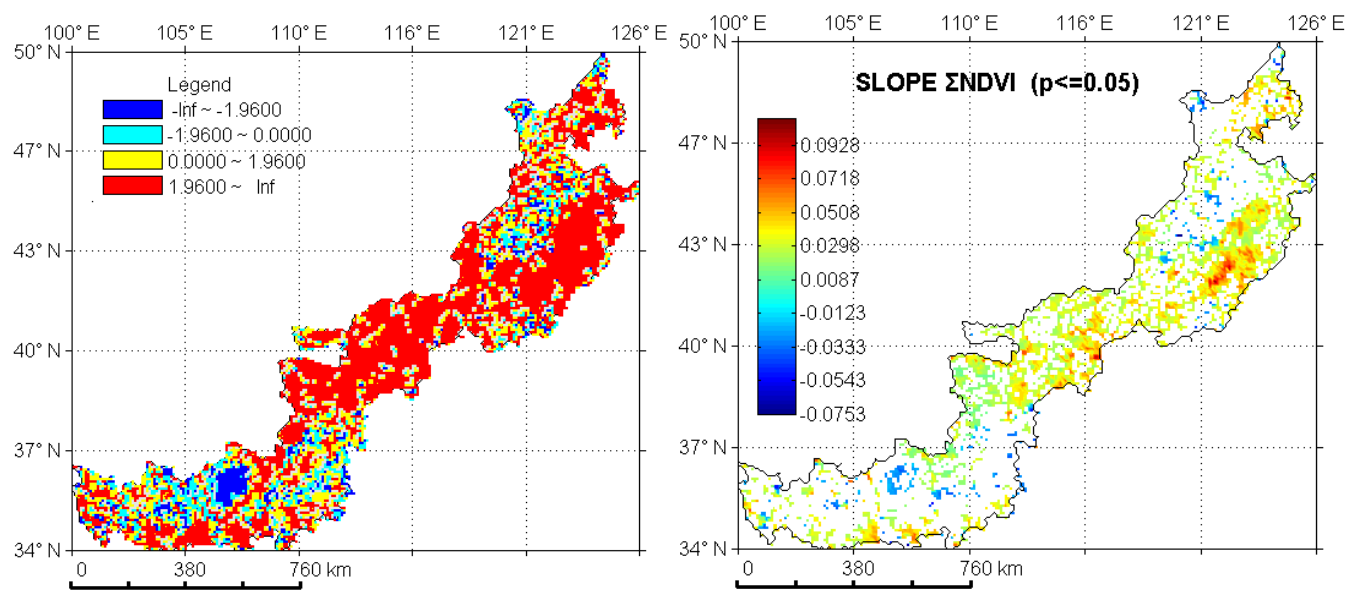

Fig.5. Maps of $\Sigma$ NDVI Mann-Kendall nonparametric test (left) and linear regression temporal trend analysis slope-values (only slopes based on trends significant at a 5\% confidence level are included, right) over time ( $\mathrm{n}=25$ years) for pixels.

\subsection{Trends in RUE}

To further understand the changes in land cover, the Mann-Kendall nonparametric test and linear regression are used to analyze the trends from 1982 to 2006 (Fig. 6). The significant trend in RUE is ( $\leq \leq 0.05$ ) calculated by two methods (Fig. 6). The northeast and central sections of the APTZNC are characterized by positive trends in RUE slope values, contrary to what was observed in the small area of the southwest section.

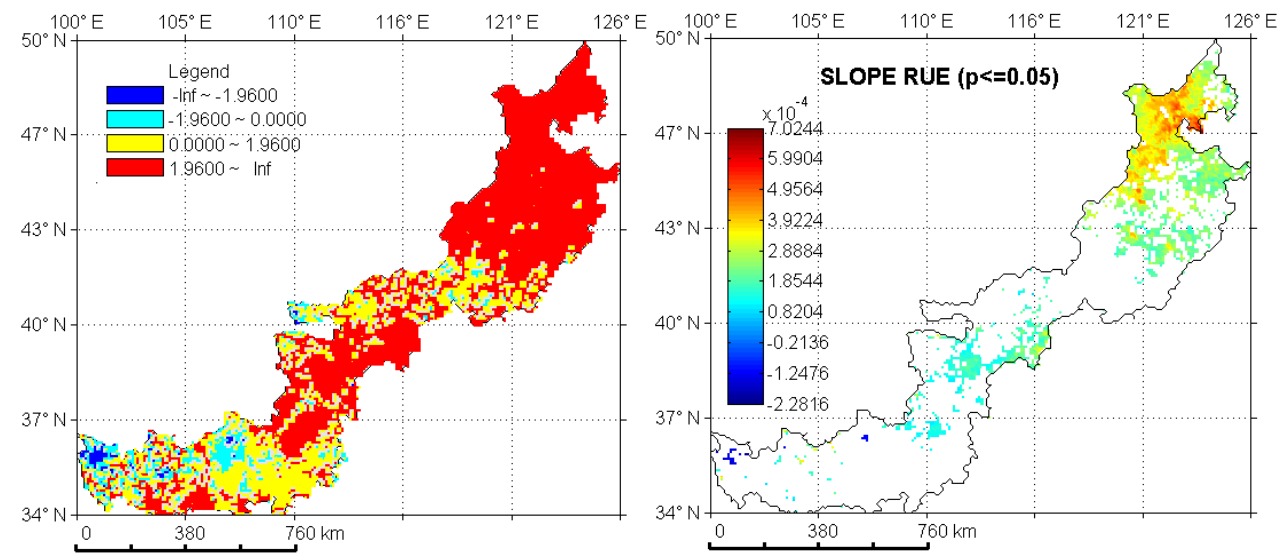

Fig.6. Maps of RUE Mann-Kendall nonparametric test (left) and linear regression temporal trend analysis slope-values (only slopes based on trends significant at a 5\% confidence level are included, right) over time ( $\mathrm{n}=25$ years) for pixels. 


\section{DISCUSSION}

\subsection{Correlation between $\Sigma$ NDVI and rainfall}

Similar results about correlation between $\Sigma$ NDVI and rainfall have been reported in the APTZNC ${ }^{[4,19]}$. The correlation between $\Sigma$ NDVI and rainfall in the APTZNC is strong in some areas and low in others. Figure 4 shows that the annual rainfall in the study area can account for $25.20 \%$ of the variance in the $\Sigma$ NDVI and $22.13 \%$ of the variance in the $\Sigma$ NDVI green-up. This reflects the limitation of using only rainfall as an indicator which may be due to the negative effect of human activities (i.e., grazing pressure, deforestation and reforestation, chemical fertilizer use) on data precision (i.e., NDVI and rainfall). By comparison, the linear correlation between rainfall and $\Sigma$ NDVI/NDVI observed in other studies was mainly based on the meteorological data, not per-pixel data as collected in this study ${ }^{[27,28]}$.

\subsection{Comparison of annual $\Sigma$ NDVI change trends with other $\Sigma$ NDVI studies}

Significant variations in the annual $\Sigma$ NDVI are detected during 1982-2006, which are consistent with previous studies ${ }^{[3,}$ ${ }^{19,29,30]}$. Even though differences were shown for time period, scale, and accuracy, especially from different data sources, the greenness trend is in line with our results. This can be explained by the improved eco-restoration (i.e., soil and water management, prevention and control of pest diseases, "Three-Northern China" shelterbelt construction) ${ }^{[3,31]}$.

\subsection{Influence of rainfall on RUE trend}

The detected RUE through the M-K nonparametric test is divided into three classes, i.e., significantly decreased, unchanged, and significantly increased. As shown in Figure 7, the region with the annual rainfall of 200-300 mm is most prone to desertification, and decertified land area accounted for $2.49 \%$ of the region in this range. The decertified land area with annual rainfall of $300-400 \mathrm{~mm}$ and $400-500 \mathrm{~mm}$ accounted for $2.39 \%$ and $0.43 \%$ of the study area, respectively. However, desertification is rarely detected below $200 \mathrm{~mm}$ or above $500 \mathrm{~mm}$ rainfall, possibly due to the fact that $200-500 \mathrm{~mm}$ is the range for normal rainfall distribution. On the other hand, reduced rainfall does not necessarily lead to desertification. A rainfall range of $200-500 \mathrm{~mm}$ could still be treated as a threshold value, where desertification is less likely to occur with an increase in rainfall. An annual rainfall range of 400-500 $\mathrm{mm}$ significantly enhanced the vegetation productivity, which accounts for approximately $66.63 \%$ of the total area. With an increase in rainfall, vegetation restoration capacity is also enhanced.

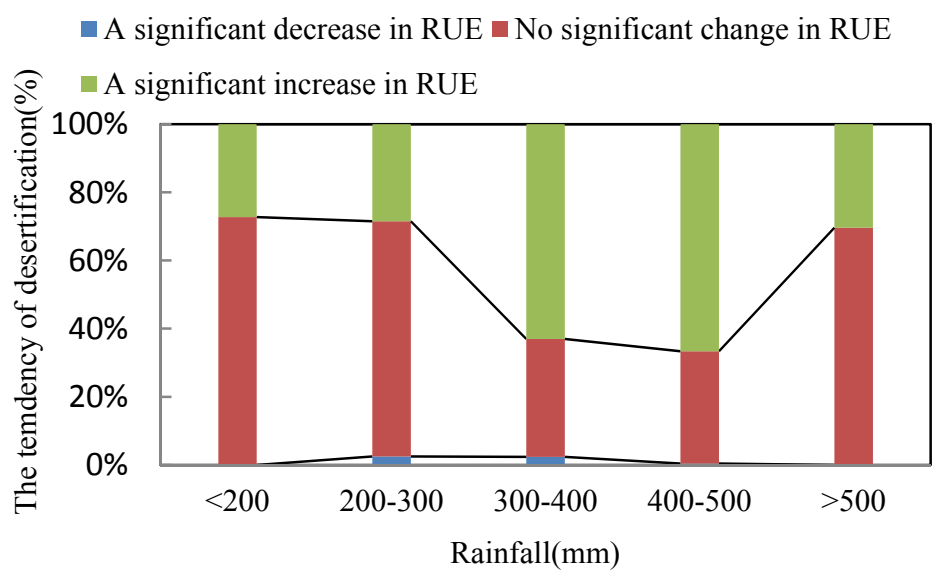

Fig.7. Desertification tendency among different rainfall conditions in the APTZNC. 


\section{CONCLUSION}

By utilizing both the AVHRR GIMMS NDVI dataset from 1982 to 2006 and meteorological data, we investigated the relationship between annual $\Sigma$ NDVI and rainfall with the Pearson correlation method, trends in annual $\Sigma$ NDVI and RUE with the M-K nonparametric test and linear regression temporal trend analysis methods in the Agro-Pastoral Transitional Zone in Northern China. There was no significant correlation between annual NNDVI and rainfall during 1982-2006 in most sections of the study area. The distribution of rainfall cannot fully explain the patterns of vegetation growth. Spatial-temporal variations were observed in the study area from 1982-2006. An increasing trend was detected in the vegetation changes in the main section of the study area. Positive trends in RUE slope values were mainly distributed in

the northeast and central sections of APTZNC, yet opposite results were found in the southwestern section. The range of 200-500 mm rainfall can be seen as a certain threshold value, desertification will be less likely to occur, and vegetation restoration capacity will be enhanced with increased rainfall.

\section{ACKNOWLEDGEMENTS}

This work was supported by the National Basic Research Program of China (973) (No. 2010CB951603), the National Natural Science Foundation of China (No. 41171334 and 41071278), Ecological Innovation \& Breeding Project (No. Y254021031,355031061), USDA NIFA Project (No. 2010-34263-21075), the Research Fund for the Doctoral Program of Higher Education (No. 20100076120024), and the Fundamental Research Funds for the Central Universities of Ministry of Education (East China Normal University). We would like to thank GIMMS and the National Meteorological Center of China for providing the necessary information.

\section{REFERENCES}

[1] Nemani, R.R., Keeling, C.D., Hashimoto, H., Jolly, W.M., Piper, S.C., Tucker, C.J., Myneni, R.B., and Running, S.W. "Climate-driven increases in global terrestrial net primary production from 1982 to 1999," Science, 300(5625), 1560-1563(2003).

[2] Warren, A., “The policy implications of Sahelian change,” J. Arid Environ., 63(3), 660-670(2005).

[3] Li, Y.C., Gong, P., Liu, C.X., Chen, J., and Yu, D.Y., "Vegetation Cover Changes and Correlation with Climatic Factors in Northern China during 1982 1999," Resources Science, 28(2), 109-117(2006).

[4] Helldén, U., and Tottrup, C., "Regional desertification: A global synthesis," Global Planet. Change, 64(3-4), 169-176(2008).

[5] LeHouerou, H.N., "Rain use efficiency: a unifying concept in arid-land ecology," J. Arid Environ., 7(3), 213-247(1984).

[6] Fensholt, R., Sandholt, I., Rasmussen, M.S., Stisen, S., and Diouf, A., "Evaluation of satellite based primary production modelling in the semi-arid Sahel," Remote Sens. Environ., 105(3), 173-188(2006).

[7] Prince, S.D., De Colstoun, E.B. and Kravitz, L.L., "Evidence from rain-use efficiencies does not indicate extensive Sahelian desertification," Global Change Biol., 4(4), 359-374(1998). 
[8] Running, S.W., Nemani, R.R., Heinsch, F.A., Zhao, M., Reeves, M., and Hashimoto, H., "A continuous satellite-derived measure of global terrestrial primary production,” Bioscience, 54(6), 547-560(2004).

[9] Fensholt, R., and Rasmussen, K., "Analysis of trends in the Sahelian 'rain-use efficiency' using GIMMS NDVI, RFE and GPCP rainfall data," Remote Sens. Environ., 115(2), 438-451(2011).

[10] Prince, S.D., Wessels, K.J., Tucker, C.J., and Nicholson, S., "Desertification in the Sahel: a reinterpretation of a reinterpretation," Global Change Biol., 13(7), 1308-1313(2007).

[11] Prince, S.D., Becker-Reshef, I. and Rishmawi, K., "Detection and mapping of long-term land degradation using local net production scaling: Application to Zimbabwe,” Remote Sens. Environ., 113(5), 1046-1057(2009).

[12] Martínez, B., Gilabert, M.A., García-Haro, F.J.,Faye, A.,and Meliá,J., "Characterizing land condition variability in Ferlo, Senegal (2001-2009) using multi-temporal 1-km Apparent Green Cover (AGC) SPOT Vegetation data," Global Planet. Change, 76(3-4), 152-165(2011).

[13] Jarlan, L., Mangiarotti, S., Mougin, E., Mazzega, P., Hiernaux, P., and Le Dantec, V., "Assimilation of SPOT/VEGETATION NDVI data into a sahelian vegetation dynamics model," Remote Sens. Environ., 112(4), 1381-1394(2008).

[14] Fensholt, R., Rasmussen, K., Nielsen, T. T., and Mbow, C., "Evaluation of earth observation based long term vegetation trends-Intercomparing NDVI time series trend analysis consistency of Sahel from AVHRR GIMMS, Terra MODIS and SPOT VGT data,” Remote Sens. Environ., 113(9), 1886-1898(2009).

[15] Narentuya, Liu, S.W., Fan, X.L., and Tian, M.Z., "Geomorphical Features of The Badain Jaran Desert Lakes and Their Surrounding Based on RS And GIS Methods,'IJACT, 4(15), 74-80(2012).

[16] Huang, J.J., Wu, Y.Y., Wu, Y.X., Zhan, Y.J., and Wu, H.,"Analysis of Spatio-temporal Changes of Land Use in Wuhan City Using Remote Sensing and GIS,'JJACT, 4(1), 215-222(2012).

[17] Zhao, H. L., Zhao, X. Y., Zhang, T.H., and Zhou, R.L., "Boundary Line on Agro-Pasture Zigzag Zone In North China and its Problems on Eco-Environment," Advance in Earth Sciences, 17(5), 739-747(2002).

[18] Tucker, C.J., Pinzon, J.E., Brown, M.E., Slayback, D., Pak, E., Mahoney, R., Vermote, E. and Saleous, N., “An extended AVHRR 8 - km NDVI dataset compatible with MODIS and SPOT vegetation NDVI data," Int. J. Remote Sens., 26(20), 4485-4498(2005).

[19] Fensholt, R., and Proud, S. R., "Greenness in semi-arid areas across the globe 1981-2007 — an Earth Observing Satellite based analysis of trends and drivers," Remote Sens. Environ., 121, 144-158(2012).

[20] Chen,J., Jo"nssonc, P., Tamurab, M., Gua, Z., Matsushitab, B.,and Eklundh, L., "A simple method for reconstructing a high-quality NDVI time-series data set based on the Savitzky-Golay filter," Remote Sens. Environ.,91(3-4),332-344(2004).

[21] Shen, M., Tang, Y., Chen, J., Zhu, X., and Zheng, Y., "Influences of temperature and precipitation before the growing season on spring phenology in grasslands of the central and eastern Qinghai-Tibetan Plateau," Agr. Forest Meteorol., 151(12), 1711-1722(2011).

[22] Peng, J., Liu, Z., Liu, Y., Wu, J., and Han, Y., “Trend analysis of vegetation dynamics in Qinghai-Tibet Plateau using Hurst Exponent,” Ecol. Indic., 14(1), 28-39(2012).

[23] Mao, D., Wang, Z., Luo, L., Ren, C., "Integrating AVHRR and MODIS data to monitor NDVI changes and their relationships with climatic parameters in Northeast China,” Int. J. Appl. Earth Obs., 18, 528-536(2012).

[24] Zhang, S., and Lu, X.X., "Hydrological responses to precipitation variation and diverse human activities in a mountainous tributary of the lower Xijiang, China," Catena, 77(2), 130-142(2009). 
[25] Qiu, H.J., and Cao, M.M., "Spatial and Temporal Variations in Vegetation Cover in China Based on SPOT Vegetation Data," Resources Science,33(2), 335-340(2011).

[26] Li, J., Lewis, J., Rowland, J., Tappan, G., and Tieszen, L.L., "Evaluation of land performance in Senegal using multi-temporal NDVI and rainfall series," J. Arid Environ., 59(3), 463-480(2004).

[27] Bai, Y., Wu, J.G., Xing, Q., Pan, Q.M., Huang, J.H, Yang, D.L., and Han, X.G., "Primary production and rain use efficiency across a precipitation gradient on the Mongolia plateau," Ecology, 89(8), 2140-2153(2008).

[28] Song, Y., and Ma, M.G., "Variation of AVHRR NDVI and its Relationship with Climate in Chinese Arid and Cold Regions," J. Remote Sens., 12(3), 499-505(2008).

[29] Mao, R., Gong, D.Y., and Fang, Q.M., "Comparison Analysis of Environmental Changes between Sahel and Agro-pastoral Zone in Northern China," Progress in Geography, 26(4), 51-63(2007).

[30] Yin, H., Li, Z.G., Wang, Y.L., and Cai, F., "Assessment of Desertification Using Time Series Analysis of Hyper-temporal Vegetation Indicator in Inner Mongolia,” Acta Geographica Sinica, 66(5), 653-661(2011).

[31] Wang, Q., Zhang, B., Dai, S.P., Zou, Y., Ma, Z.H., and Zhang, Y.N.,"Dynamic Changes in Vegetation Coverage in the Three-North Shelter Forest Program Based on GIMMS AVHRR NDVI," Resources Science, 33(8), $1613-1620(2011)$. 